\title{
Effect of Cr on microstructure and oxidation behavior of TiAl-based alloy with high $\mathrm{Nb}$
}

\author{
Zhu-Hang Jiang', Cheng-Zhi Zhao', Jiao-Jiao Yu', *He-Xin Zhang', and Zhi-Ming Li' \\ 1. Key Laboratory of Superlight Materials and Surface Technology, College of Materials Science and Chemical Engineering, Harbin Engineering \\ University, Harbin 150001, China; \\ 2. College of Power and Energy Engineering, Harbin Engineering University, Harbin 150001, China
}

\begin{abstract}
Three novel multi-microalloying TiAl-based alloys containing high $\mathrm{Nb}$ were designed and fabricated. Thermogravimetric method was applied to investigate the influence of $\mathrm{Cr}$ on the oxidation behavior of high $\mathrm{Nb}$ TiAl alloy at $1,073 \mathrm{~K}$ for $200 \mathrm{~h}$ in laboratory air. The 2 at.\% and 4 at.\% $\mathrm{Cr}$ were added into the alloy, (respectively named $2 \mathrm{Cr}$ and $4 \mathrm{Cr}$ compared to the $\mathrm{Cr}$-free ternary alloy, $\mathrm{OCr}$ alloy). The alloys' microstructure and composition as well as the composition distribution of the oxidation scale were analyzed by means of Scanning Electron Microscopy (SEM), Energy Dispersive Spectroscopy (EDS), and X-Ray Diffractometry (XRD). The results show that the addition of $\mathrm{Cr}$ decreases the grain size of the $\mathrm{Nb}$-TiAl alloy and leads to a transformation from a fully lamellar structure to a nearly fully lamellar structure. When oxidized at $1,073 \mathrm{~K}$ for $200 \mathrm{~h}$, the oxidized mass gain of the alloy increases with an increase in $\mathrm{Cr}$ addition amount in the first $100 \mathrm{~h}$ and decreases in the last $100 \mathrm{~h}$. With the increase of $\mathrm{Cr}$ content, the oxidation surface turns compact but uneven in morphology, which may affect the oxidation resistance of the alloy by increasing the peeling off risk of the oxidation layer at friction conditions.
\end{abstract}

Key words: TiAl-based alloys; microstructure; oxidation; $\mathrm{Cr}$ addition
CLC numbers: TG146.23
Document code: A
Article ID: 1672-6421/2018)01-017-06

$\mathrm{R}$ ecently, research on lightweight materials has been an essential aspect in aircraft manufacturing and aerospace industry. The $\gamma$-TiAl based alloys with high content of $\mathrm{Nb}$ are promising candidates as a new high temperature material due to their low density, excellent specific strength, specific stiffness, and good high temperature oxidation and creep resistance ${ }^{[1,2]}$. Compared with nickel-based superalloy, which has been widely used for more than fifty years, TiAl alloy containing high $\mathrm{Nb}$ is lighter in weight. The high $\mathrm{Nb}$ TiAl alloy exhibits superior creep properties and high temperature oxidation resistance compared to normal TiAl based alloy over $973 \mathrm{~K}^{[1-9]}$.

TiAl-based alloys have high mechanical strength both at room and high temperatures because of their ordered structure, but single $\gamma$ phase TiAl-based alloys have very low room temperature ductility. The near $\gamma$ phase TiAl based alloy shows better ductility with the presence of a small amount of the second $\alpha_{2}$ phase. The microstructure of the near $\gamma$ phase is of $\alpha_{2}-\gamma$ layered structure which is called full lamellar structure. The

\section{*He-Xin Zhang}

Famale, born in 1981, Ph.D. Her research mainly focuses on high temperature alloys and composites.

E-mail: zhanghx@hrbeu.edu.cn

Received: 2017-03-28; Accepted: 2017-08-23 room temperature ductility of the near $\gamma$ phase TiAl based alloy is closely related to the grain size and microstructure distribution. Small grain size and good grain boundary strength can significantly improve the toughness of the alloy. One of the most interesting approaches to decrease grain size is micro-multicomponent alloying, in which a variety of alloying elements are added in trace amounts. The near $\gamma$-phase TiAl-based alloys have very good solid solubility for many alloying elements, so micro-multi-component alloying is very effective for the microstructure optimization of the material. Alloying elements such as $\mathrm{Cr}, \mathrm{B}, \mathrm{Si}$ and $\mathrm{W}$ are usually added in the TiAl alloy. It has been found that the addition of $\mathrm{Nb}$ can significantly improve the high temperature oxidation resistance of TiAl alloy ${ }^{[14-19]}$. The addition of alloying elements such as $\mathrm{Cr}$, Mn and V may improve the plastic deformation properties of TiAl-based alloys. It is also proved that the high addition amount of $\mathrm{Cr}(<8 \mathrm{at} . \%)$ has a good effect on the high temperature oxidation resistance at a temperature higher than $1,073 \mathrm{~K}^{[13]}$, but excess $\mathrm{Nb}$ and $\mathrm{Cr}$ addition may lead to poor ductility at room temperature ${ }^{[10-12]}$. Therefore, it is necessary to determine the effect of $\mathrm{Cr}$ on the microstructure evolution and oxidation behavior of TiAl-based alloys with high $\mathrm{Nb}$.

In this study, in order to determine the effect of 
$\mathrm{Cr}$ on microstructure and oxidation resistance of the alloys, a low range of atom percentage of $\mathrm{Cr}(<5 \mathrm{at} . \%)$ was added to TiAl-based alloy with a high content of $\mathrm{Nb}$ (8at.\%). At the same time, $0.8 \% \mathrm{~B}, 0.2 \% \mathrm{Si}$ and $0.5 \% \mathrm{~W}$ were added, focusing on strengthening the grain boundary by solid solution strengthening effect so as to improve the strength of the alloy. In addition, high temperature oxidation behavior of the three novel TiAl alloys with different percentages of $\mathrm{Cr}$ was investigated.

\section{Experimental procedures}

\subsection{Specimen preparation}

The three novel designed alloys are Ti-45Al-8Nb-0.2Si-0.5W$0.8 \mathrm{~B}$, Ti-45Al-8Nb-2Cr-0.2Si-0.5W-0.8B, and Ti-45Al-8Nb$4 \mathrm{Cr}-0.2 \mathrm{Si}-0.5 \mathrm{~W}-0.8 \mathrm{~B}$. The raw materials used include pure $\mathrm{Al}$ $(\geqslant 99.9 \%)$, titanium sponge $(\geqslant 99.7 \%)$, pure niobium ( $\geqslant 99.8 \%)$, $\mathrm{Cr}(\geqslant 99.98 \%)$, Mo ( $\geqslant 99.7 \%), \mathrm{W}(\geqslant 99.95 \%)$, and AlB alloy $(2.5 \%-3.5 \%$ mass fraction of B). Vacuum melting was applied to cast the materials into button ingots in a non-self-consumed tungsten electrode argon arc vacuum furnace. Before melting, the furnace was firstly vacuumed to $0.005 \mathrm{~Pa}$, then argon was used as a protective gas and pressured in the furnace, and finally stabilized at $0.03 \mathrm{~Pa}$. The melting process was repeated four times for material homogenization through the overturning platform. Then, the melt was cooled down in water cooled copper crucible into button ingots of around $40 \mathrm{~g}$. The ingots were cut into small specimens with the dimension of $10 \mathrm{~mm} \times 10 \mathrm{~mm} \times 1 \mathrm{~mm}$ after homogenization treatment in $\alpha$-phase region $(1,473 \mathrm{~K})$ for $24 \mathrm{~h}$. Then the specimens experienced a cyclic heat treatment, which is a three-time heat treatment at $1,423 \mathrm{~K}$ for $4 \mathrm{~h}$ with air cooling. The homogenization treatment can reduce the micro segregation of the composition. The cyclic heat treatment is aimed for obtaining a fine microscopic fully lamellar microstructure, since a three-time heat treatment allows better transformation from original $\alpha$ phase to $\alpha_{2}-\gamma$ laminar phase. The air cooling afterwards may further refine the grain. After the heat treatment, the ingots were polished using mesh number $1500 \mathrm{SiC}$ water proof abrasive papers before being cleaned in acetone for 15 min using an ultrasonic cleaning machine.

\subsection{Isothermal oxidation}

Isothermal oxidation experiment was carried out at 1,073 K for $200 \mathrm{~h}$ under $1 \mathrm{~atm}$ using a chamber electric furnace. The specimens were moved out of the furnace after a certain fixed period of time. Their mass gain was measured by electric balance with a resolution of $0.01 \mathrm{mg}$ after cooling down to room temperature. At least two specimens were tested at a time so as to minimize data error.

\subsection{Microstructure observation}

The ingots were tested by a back-scattered scanning electron microscope (SEM) before and after heat treatment. The oxidation samples were also examined by SEM. For the purpose of observing oxidation section, specimens were cut perpendicular to the surface of oxide and were ground using 2000 grit silicon carbide paper before etching. For oxidation surface observation, no special treatments are needed except keeping it clean. In order to find out the structure of oxidation scales, line scanning and EDS analysis were used for oxide layer composition analysis.

\section{Results and discussion}

Figures 1(a), (c) and (e) are ingots of $0 \mathrm{Cr}, 2 \mathrm{Cr}$ and $4 \mathrm{Cr}$ alloy in as-cast condition, while Figs. 1(b), (d) and (f) are ingots after heat treatment.

It can be found from Fig. 1 that $0 \mathrm{Cr}$ alloy is of fully lamellar microstructure in as-cast condition, which transformed to near fully lamellar microstructure with smaller grain size and thinner interlamellar spacing after heat treatment. Fully lamellar microstructure is composed of alternating lamellae of $\alpha_{2}-\mathrm{Ti}_{3} \mathrm{Al}$ and $\gamma$-TiAl. It has been found that fully lamellar structure of $\gamma$-TiAl intermetallics is beneficial to the fracture toughness and high-temperature strength, but the room temperature ductility of the alloy is poor due to the inhomogeneous distribution of $\gamma$-TiAl intermetallics in as-cast condition ${ }^{[14-16]}$. The microstructure after heat treatment can surely improve the mechanical properties of the alloy by refining grain size and improving component homogeneity. The appearance and increase of single $\gamma$ phase at the grain boundary of the original $\alpha_{2}-\gamma$ fully lamellar structure comes from a transformation from high-temperature $\alpha$ to highly faulted $\gamma$ phase, which commonly occurs in the rapid cooling process that suppresses diffusion. The result of the transformation is the increase of $\gamma$ phase and decrease of $\alpha_{2}-\gamma$ layer combination, i.e. decomposition of the mixture of $\alpha_{2}$ and $\gamma$ to single $\gamma$ phase.

In general, there was a transformation from $\alpha$ phase to $\gamma$ phase for $2 \mathrm{Cr}$ and $4 \mathrm{Cr}$ alloys after heat treatment, which formed a better near fully lamellar microstructure. The $2 \mathrm{Cr}$ alloy showed smaller grain size and thinner layer space after heat treatment, while $4 \mathrm{Cr}$ alloy barely changed in grain size. This means that the increase of $\mathrm{Cr}$ content in the alloy can effectively refine the grain size of the alloy, and that the heat treatment process has a more obvious grain refinement effect on the lower Cr content alloy.

After heat treatment, the single-phase $\gamma$ phase was precipitated at the grain boundary of the $\alpha_{2}-\gamma$ lamellar structure, resulting in a better grain boundary oxidation resistance of the alloy, because the $\gamma$-TiAl phase could produce more $\mathrm{Al}_{2} \mathrm{O}_{3}$ on the oxidation layer and provide better oxidation protection than the $\alpha_{2}-\mathrm{Ti}_{3} \mathrm{Al}$ phase.

The isothermal oxidation kinetics of $0 \mathrm{Cr}, 2 \mathrm{Cr}$ and $4 \mathrm{Cr}$ alloys under laboratory air at $1,073 \mathrm{~K}$ are shown in Fig. 2. The mass gain of $0 \mathrm{Cr}, 2 \mathrm{Cr}$ and $4 \mathrm{Cr}$ alloys were $0.52684,0.63218$ and $0.67203 \mathrm{mg} \cdot \mathrm{cm}^{-2}$, respectively, after $200 \mathrm{~h}$ oxidation, which are much lower than that of conventional TiAl binary alloy, about $1 \mathrm{mg} \cdot \mathrm{cm}^{-2}$ or more at similar oxidation condition ${ }^{[14]}$. It is clear that all three alloys have superior oxidation resistance compared with the conventional TiAl based alloy. There are two points that 

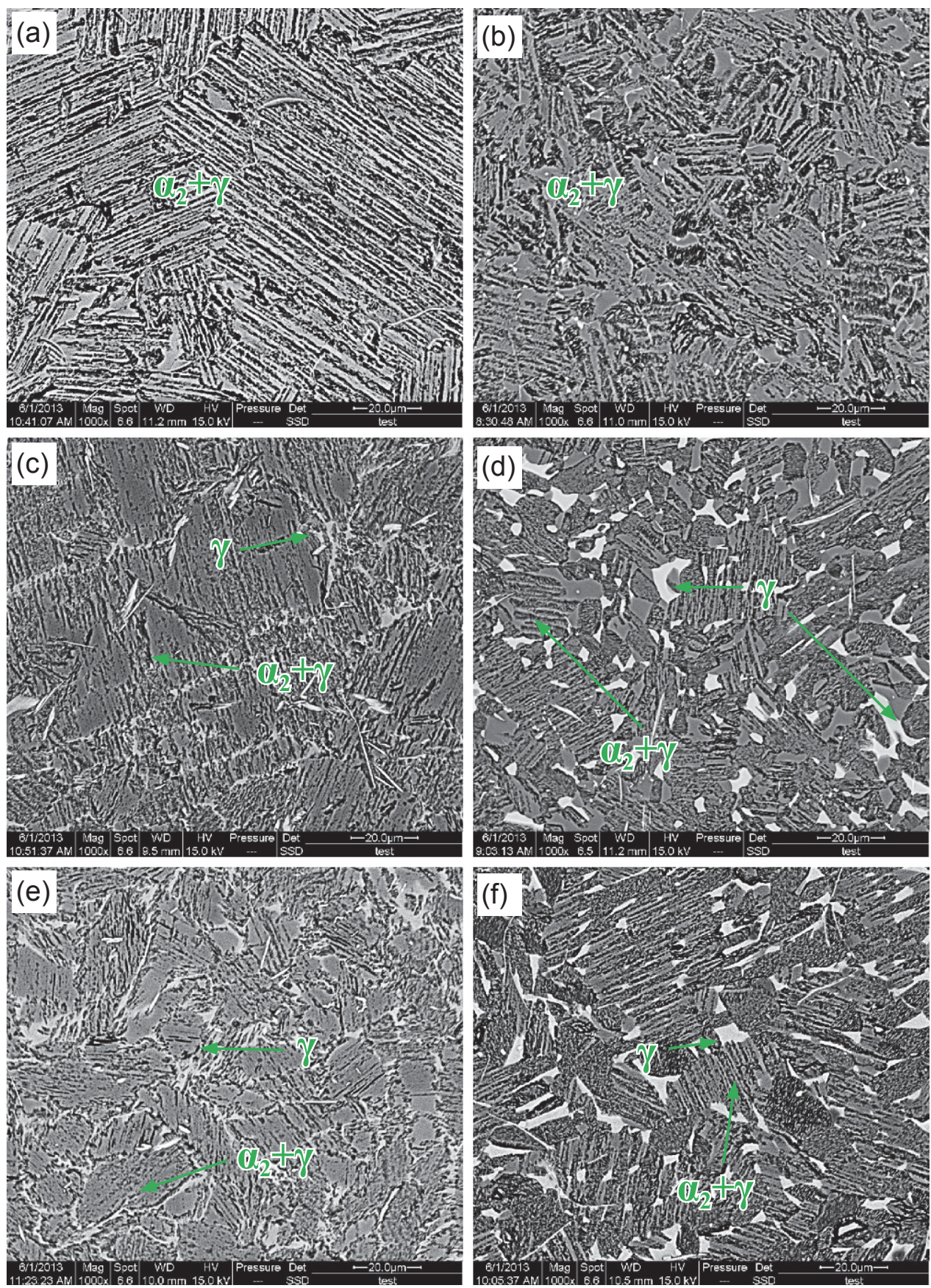

Fig. 1: Back-scattered SEM metallograph of $0 \mathrm{Cr}$ alloy (a and b), $2 \mathrm{Cr}$ alloy (c and d), $4 \mathrm{Cr}$ alloy (e and f) (a, $c$ and $e$ are in as-cast condition, b, $d$ and $f$ are heat-treated)

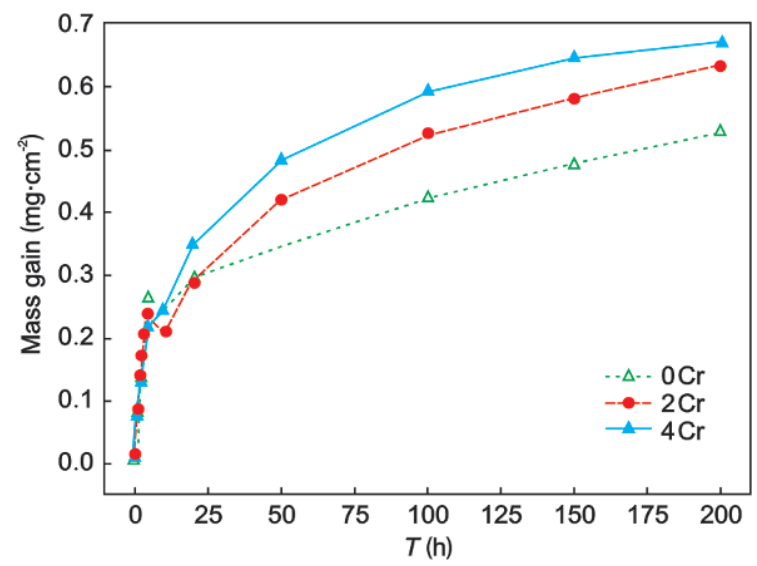

Fig. 2: Isothermal oxidation kinetics at 1,073 K: (a) $0 \mathrm{Cr}$ alloy, (b) $2 \mathrm{Cr}$ alloy, (c) $4 \mathrm{Cr}$ alloy should be noticed in the kinetics results: firstly, the final mass gain increases with an increase in $\mathrm{Cr}$ content in a quite small range. Secondly, increase of $\mathrm{Cr}$ content slows down the mass gain rate, while $0 \mathrm{Cr}$ alloy keeps an almost fixed rate of about $1.31 \times 10^{-3} \mathrm{mg} \bullet\left(\mathrm{cm}^{2} \cdot \mathrm{h}\right)^{-1}$. As for $2 \mathrm{Cr}$ alloy, the oxidation rate changed from $5.27 \times 10^{-3} \mathrm{mg} \cdot\left(\mathrm{cm}^{2} \cdot \mathrm{h}\right)^{-1}$ in the first $50 \mathrm{~h}$ to $1.05 \times 10^{-3}$ $\mathrm{mg} \cdot\left(\mathrm{cm}^{2} \cdot \mathrm{h}\right)^{-1}$ in the last $100 \mathrm{~h}$, which is $1 / 5$ of that in the first $50 \mathrm{~h}$, and much lower than that of $0 \mathrm{Cr}$ alloy.

It is clear that the oxidation scale increases along with $\mathrm{Cr}$ addition in the first $100 \mathrm{~h}$. In the last $100 \mathrm{~h}$, the oxidation mass gain increase of $4 \mathrm{Cr}$ alloy was $0.08064 \mathrm{mg} \cdot \mathrm{cm}^{-2}$, which is the least of all in this period, while $0 \mathrm{Cr}$ alloy was oxidized in 0.10537 $\mathrm{mg} \cdot \mathrm{cm}^{-2}$, which highlighted that $\mathrm{Cr}$ has a long term oxidation resistance for high $\mathrm{Nb}$-TiAl alloy. After the first $50 \mathrm{~h}$, as the 
$\mathrm{Cr}$ content increases, the curve changes from near straight to convex, which may be due to the fact that the oxidized surface formed by $\mathrm{Cr}$ addition became more compact and thus slowed down the rate of oxidation.

The SEM micrographs in Fig. 3 show the morphology of the oxide formed on those three alloys after $200 \mathrm{~h}$ oxidation. Figure 3(a) for $0 \mathrm{Cr}$ alloy shows the most compact and continuous structure in the three alloys. Some projections are clearly observed in Fig. 3(b), as are circled in the figure, probably caused by the growing addition of $\mathrm{Cr}$. For the $4 \mathrm{Cr}$ alloy in Fig. 3 (c), there are many nodular oxidation structures appearing on the oxidation surface, which seems to be a joining of the oxidation structure in Fig. 3(b), but larger in size and more diffuse in distribution. These oxidative structures may have a certain relationship with the chromium oxide and directly lead to accelerated oxidation of the alloy within the first $100 \mathrm{~h}$.
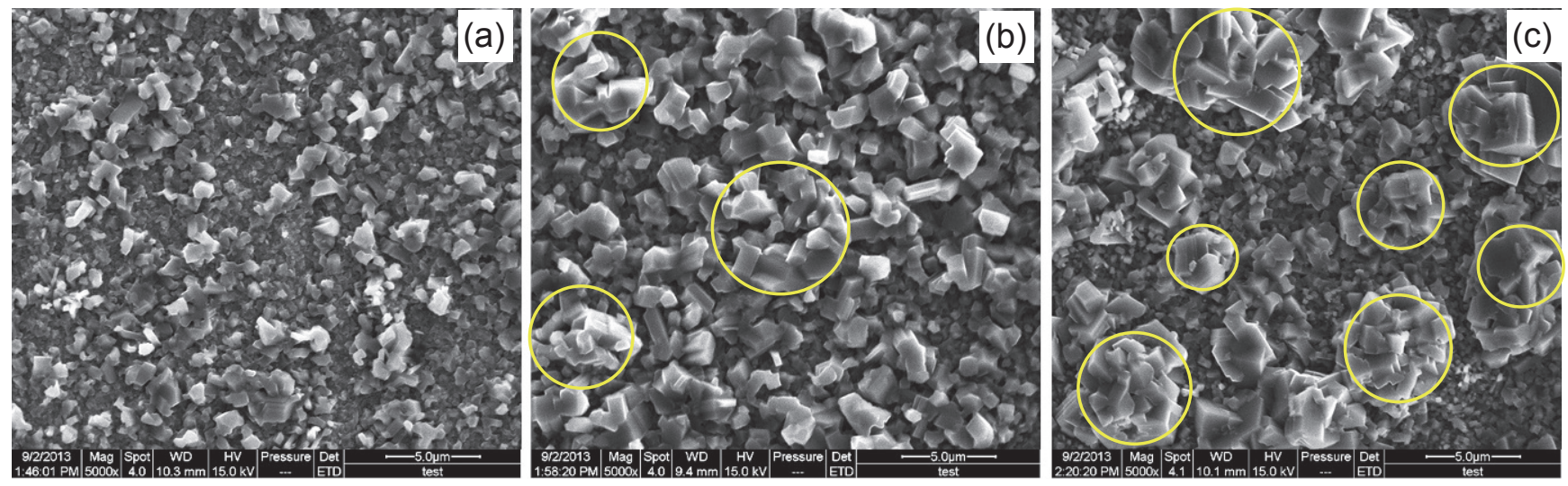

Fig. 3: SEM scanning of oxidized surface: (a) $0 \mathrm{Cr}$ alloy, (b) $2 \mathrm{Cr}$ alloy, (c) $4 \mathrm{Cr}$ alloy

The section SEM scanning results in Fig. 4 clearly shows the change in oxidation structure from $0 \mathrm{Cr}$ to $\mathrm{Cr}$-added alloys $(2 \mathrm{Cr}$ and $4 \mathrm{Cr}$ alloys). There are three oxidation layers in $0 \mathrm{Cr}$ alloy, and the inner layer is thicker than the other two layers. As has been learned from the kinetics curves in Fig. 2, the $0 \mathrm{Cr}$ alloy oxidizing mass gain increased at an almost fixed rate, which means the matrix of the ingot kept reacting with air and the inner layer of the oxidation scale kept increasing in width. As a result, $0 \mathrm{Cr}$ alloy has the largest range of oxidation scale ( $4.8 \mu \mathrm{m}$ in average) in the three alloys (3.8 $\mu \mathrm{m}$ for $2 \mathrm{Cr}$ alloy and $2.9 \mu \mathrm{m}$ for $4 \mathrm{Cr}$ alloy). There are two oxidation layers in both $2 \mathrm{Cr}$ and $4 \mathrm{Cr}$ alloys, which differ from that of the Cr-free alloy.

The oxidation surfaces of three alloys were tested by X-Ray Diffractometry (XRD), as shown in Fig. 5. The oxidation surfaces of the three alloys mainly consist of $\mathrm{Ti}_{3} \mathrm{O}, \mathrm{TiO}_{2}, \mathrm{SiO}_{2}, \mathrm{NbO}$, and (Al0.9CrO.1) $)_{2} \mathrm{O}_{3}$ (a close binder of $\mathrm{Al}_{2} \mathrm{O}_{3}$ and $\mathrm{Cr}_{2} \mathrm{O}_{3}$ ), in which the $(\mathrm{A} 10.9 \mathrm{Cr} 0.1)_{2} \mathrm{O}_{3}$ oxide exists in the oxides of $2 \mathrm{Cr}$ and $4 \mathrm{Cr}$ alloys.

The line scanning tests of the transverse sections of the three alloys are shown in Fig. 6, by which we can analyze the constitution of the oxidation layers. There are three layers in $0 \mathrm{Cr}$ alloy, the same as being observed in Fig. 4. The inner oxide
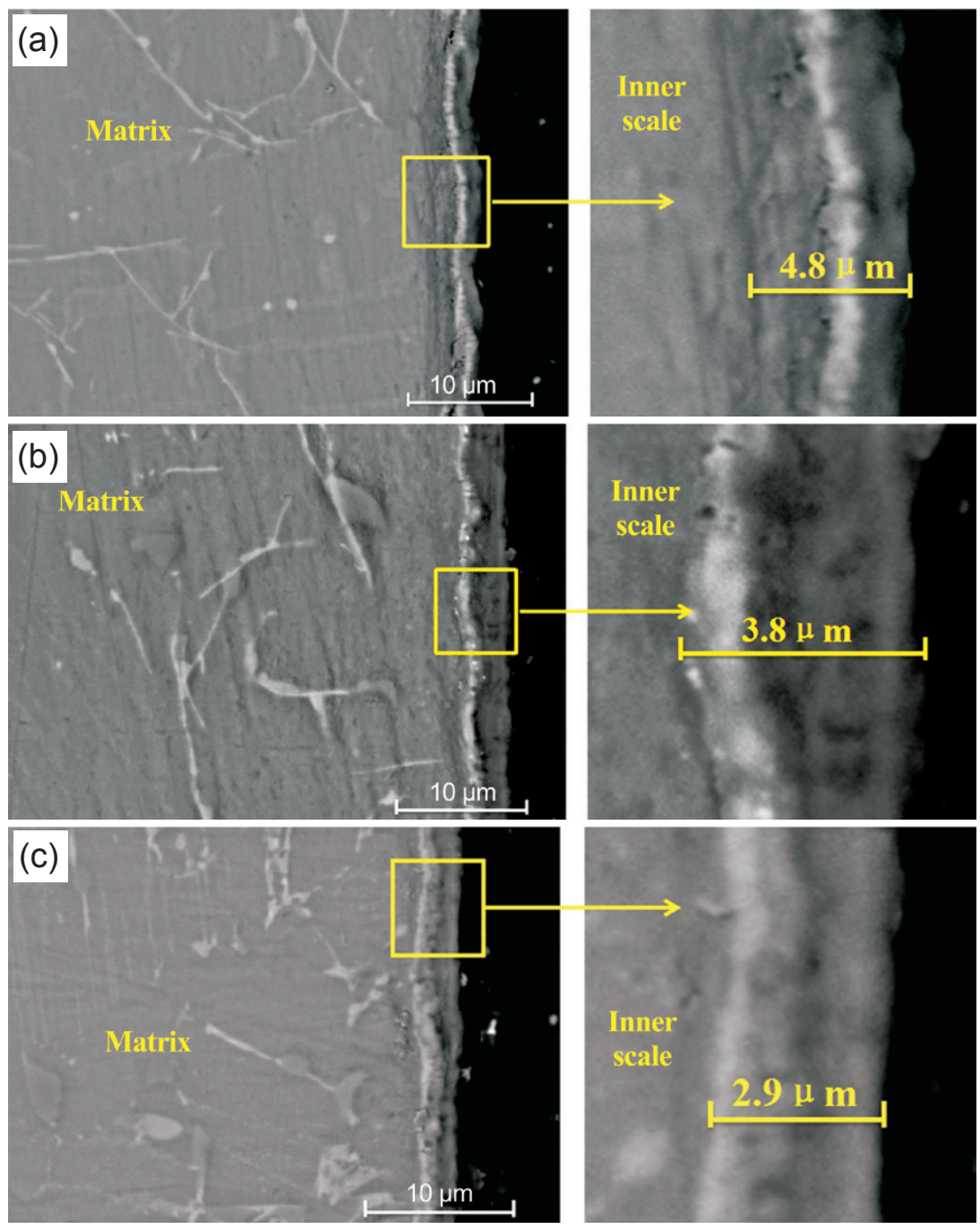

Fig. 4: SEM scanning of oxidized section: (a) $0 \mathrm{Cr}$ alloy, (b) $2 \mathrm{Cr}$ alloy, (c) $4 \mathrm{Cr}$ alloy 


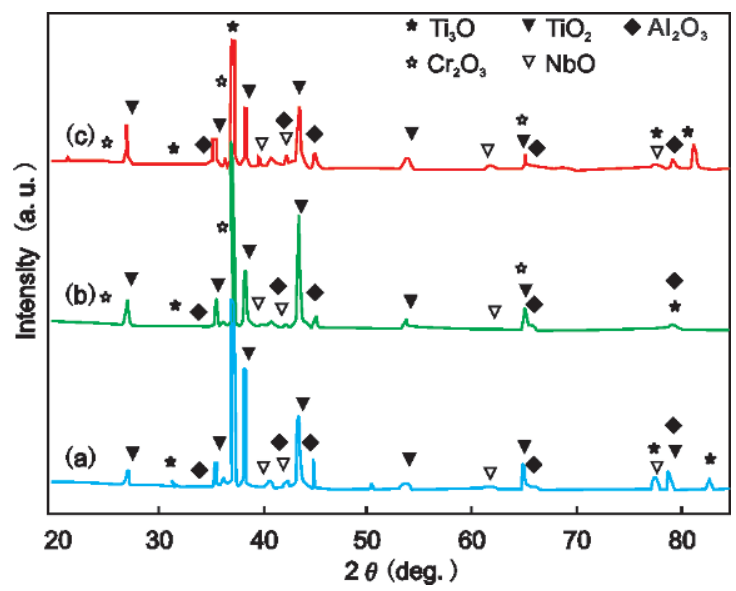

Fig. 5: X-ray diffractograms of oxidized surface: (a) $0 \mathrm{Cr}$ alloy, (b) $2 \mathrm{Cr}$ alloy, (c) $4 \mathrm{Cr}$ alloy

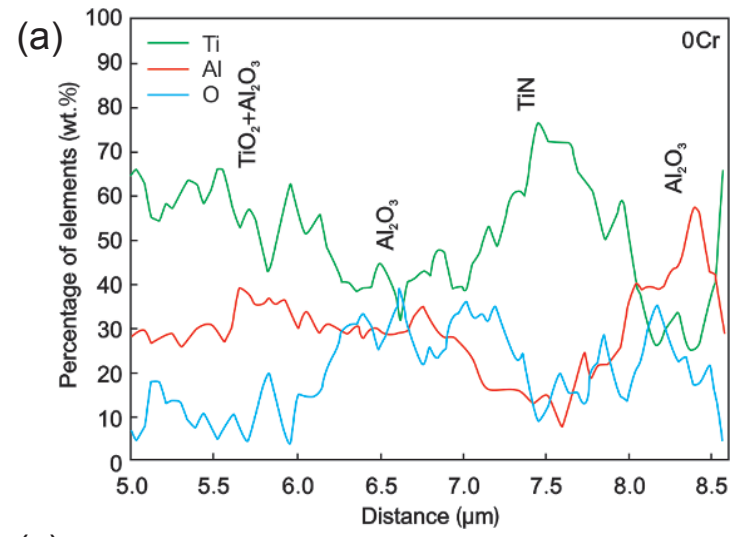

(c)

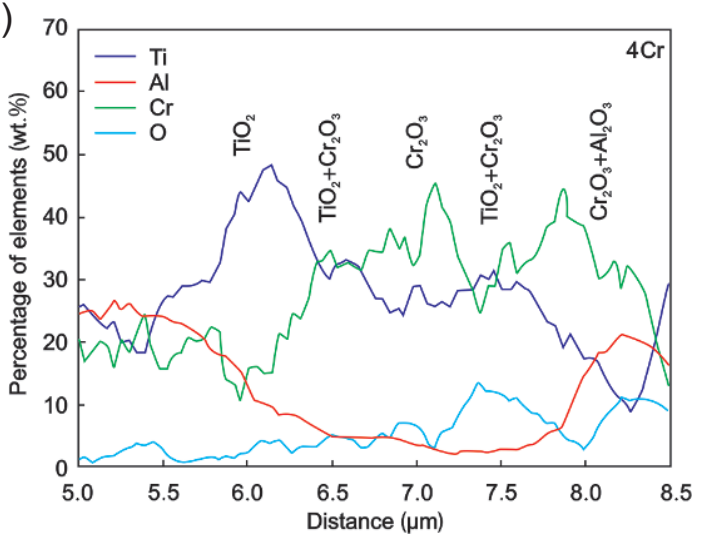

layers. The change is caused by the increasing percentage of $\mathrm{Cr}$ element into the alloy. Also, the tendency of the oxidation kinetics curve can be explained by the $\mathrm{Cr}_{2} \mathrm{O}_{3}$ increase. The rapid mass gain of $\mathrm{Cr}$-added alloys in the first $100 \mathrm{~h}$ resulted in the incompact $\mathrm{TiO}_{2} / \mathrm{Al}_{2} \mathrm{O}_{3}$ oxidation structure forming in the initial period of oxidation. With the $\mathrm{Cr}$ increasing, a large amount of oxide $\mathrm{Cr}_{2} \mathrm{O}_{3}$ joins the incompact $\mathrm{TiO}_{2}$ and $\mathrm{Al}_{2} \mathrm{O}_{3}$ oxidation structures, forming a tight and compact structure to prevent oxygen from reacting with the matrix. In addition, the volume fraction and distribution range of titanic oxides in the oxidation layers decreased with an increase in percentage of $\mathrm{Cr}$, especially in the outer layer. The outer oxidation layer is of vital importance for the oxidation resistance of an alloy because a compact and uniform oxidation surface layer can prevent the hot air from entering the matrix and reduce the risk of peeling layer is the starting position of oxidation. The matrix reacted with oxygen and formed an oxide mixture consisting of $\mathrm{TiO}_{2}$, $\mathrm{Al}_{2} \mathrm{O}_{3}$ and a small amount of $\mathrm{NbO}$. Figure 6 (a) shows that most of the protective $\mathrm{Al}_{2} \mathrm{O}_{3}$ formed on the outer layer of the $0 \mathrm{Cr}$ alloy. The intermediate oxide layer consists of titanium oxides, which is not a compact structure. The two separated layers of $\mathrm{TiO}_{2}$ and $\mathrm{Al}_{2} \mathrm{O}_{3}$ makes it hard to prevent the oxygen from entering the matrix. That means the oxidation structure formed in $0 \mathrm{Cr}$ alloy cannot supply a continuous protection for the matrix alloy from further oxidation. There are mainly two oxidation layers in $2 \mathrm{Cr}$ alloy. The inner layer is composed of titanic oxide, chromic oxide and their mixture. The outer layer comprises $\mathrm{Al}_{2} \mathrm{O}_{3}$ and $\mathrm{Cr}_{2} \mathrm{O}_{3}$. As for the $4 \mathrm{Cr}$ alloy, the layer composition is similar to the $2 \mathrm{Cr}$ alloy, but there is a larger range and a greater volume fraction of $\mathrm{Cr}_{2} \mathrm{O}_{3}$ in the oxidation

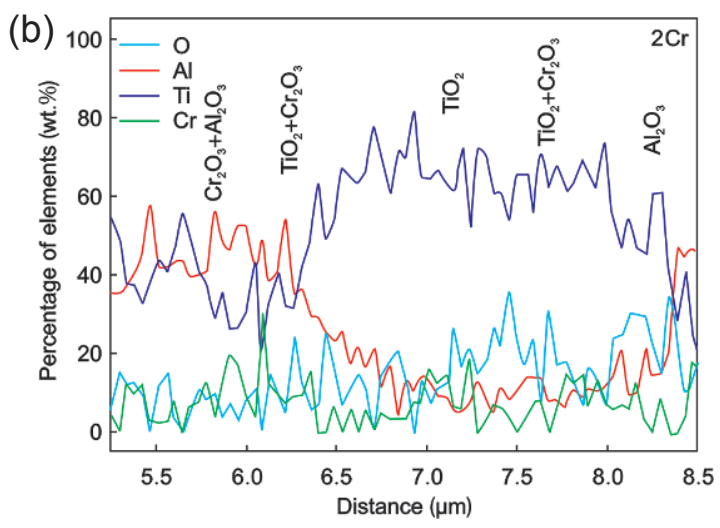

Fig. 6: EDS analysis of main oxides in oxidation section: (a) $0 \mathrm{Cr}$ alloy, (b) $2 \mathrm{Cr}$ alloy, (c) 4Cr alloy: from inner layer (distance $<5.5 \mu \mathrm{m}$ ) to oxidation surface (distance $=8.5 \mu \mathrm{m}$ )

off. The addition of 4at.\% $\mathrm{Cr}$ has a good oxidation resistance when the $\mathrm{Cr}$ oxide forms and distributes in the full range of the oxidation layers. The oxidation surface turns rugged from $0 \mathrm{Cr}$ to $4 \mathrm{Cr}$ alloy; this change may lead to the peeling off of the oxide layer at friction process.

\section{Conclusions}

Three high Nb-TiAl alloys containing different atom percentages of $\mathrm{Cr}$, i.e. $0 \mathrm{Cr}, 2 \mathrm{Cr}$ and $4 \mathrm{Cr}$ were prepared and their microstructure evolution and antioxidant properties were studied. The conclusions can be drawn as follows:

(1) Addition of $\mathrm{Cr}$ decreases the grain size of the $\mathrm{Nb}$-TiAl alloy and leads to a transformation from $\alpha_{2}$ to $\gamma$, i.e., fully lamellar structure to nearly fully lamellar structure. 
(2) After oxidation experiments at $1,073 \mathrm{~K}$ for $200 \mathrm{~h}$, the oxidized mass gain of the alloy increases with an increase in $\mathrm{Cr}$ addition amount in the first $100 \mathrm{~h}$ and decreases in the last $100 \mathrm{~h}$.

(3) The formation of $\mathrm{Cr}$ oxide in the full range of oxidation layer, especially in the surface layer during the first $100 \mathrm{~h}$, improves the compactness and oxidation resistance of the alloy by joining $\mathrm{Cr}_{2} \mathrm{O}_{3}$ to the incompact $\mathrm{TiO}_{2}$ and $\mathrm{Al}_{2} \mathrm{O}_{3}$ oxidation structures.

(4) With the increase of $\mathrm{Cr}$ content, the oxidation surface turns compact but uneven in morphology which may decrease the oxidation resistance of the alloy by increasing the peeling off risk of oxidation layer under different friction conditions.

\section{References}

[1] Krause D, Lerch B, Locci I E. Development and evaluation of TiAl sheet structures for hypersonic applications. Materials Science \& Engineering A, 2007, 464(1): 330-342.

[2] Dimiduk D M. Gamma titanium aluminide alloys-an assessment within the competition of aerospace structural materials. Materials Science \& Engineering A, 1999, 263(2): 281-288(8).

[3] Shida $\mathrm{Y}$, Anada $\mathrm{H}$. The influence of ternary element addition on the oxidation behaviour of TiAl intermetallic compound in high temperature air. Corrosion Science, 1993 (5-8): 945-953.

[4] Taniguchi S, Uesaki K, Zhu Y C, et al. Influence of niobium ion implantation on the oxidation behaviour of TiAl under thermal cycle conditions. Materials Science \& Engineering A, 1998, 249(1): 223-232.

[5] Liu Z C, Lin J P, Li S J, et al. Effects of $\mathrm{Nb}$ and Al on the microstructures and mechanical properties of high $\mathrm{Nb}$ containing TiAl base alloys. Intermetallics, 2002, 10(7): 653-659.

[6] Yong-zhe Wang, Hong-sheng Ding, Rui-run Chen, et al. A high$\mathrm{Nb} \mathrm{TiAl}$ alloy with highly refined microstructure and excellent mechanical properties fabricated by electromagnetic continuous casting. China Foundry, 2016, 13(5): 342-345.
[7] He X, Yu Z, Lai X. Analysis of high temperature deformation behavior of a high $\mathrm{Nb}$ containing TiAl based alloy. Materials Letters, 2008, 62(26): 4181-4183.

[8] Bystrzanowski S, Bartels A, Clemens $\mathrm{H}$, et al. Creep behaviour and related high temperature microstructural stability of Ti-46Al9Nb sheet material. Intermetallics, 2005, 13(5): 515-524.

[9] Chen G, Sun Z, Zhou X. Oxidation of Intermetallic Alloys in TiAl-Nb Ternary System. Corrosion, 1992, 48(11): 939-946.

[10] Lin J P, Xu X J, Wang Y L, et al. High temperature deformation behaviors of a high $\mathrm{Nb}$ containing TiAl alloy. Intermetallics, 2007, 15: 668-674.

[11] Chen G L, Zhang L C. Deformation mechanism at large strains in a high-Nb-containing TiAl at room temperature. Materials Science \& Engineering A, 2002, 329(1): 163-170.

[12] Kesler M S, Goyel S, Rios O, et al. A study of phase transformation in a TiAINb alloy and the effect of $\mathrm{Cr}$ addition. Materials Science \& Engineering A, 2010, 527(12): 2857-2863.

[13] Huang S C, Hall E L. The effects of $\mathrm{Cr}$ additions to binary TiAlbase alloys. Metallurgical \& Materials Transactions A, 1991, 22(11): 2619-2627.

[14] Zhao Lili, Lin Junpin, Wang Yanli, et al. Early oxidation behaviors of Ti50Al and Ti45A18Nb alloys at high temperature. Acta Metallurgica Sinica, 2008.

[15] Chen H, Su Y, Luo L, et al. Influence of silicide on fracture behavior of a fully lamellar Ti-46Al-0.5W-0.5Si alloy. China Foundry, 2012, 09(2): 108-113.

[16] Jian-chong Li, Rui-run Chen, Zhi-kun Ma, et al. Effect of boron on microstructure and mechanical properties of cast Ti-44Al-6Nb ingots. China Foundry, 2015, 12(1): 9-14.

[17] Cheng T T, Willis M R, Jones I P. Effects of major alloying additions on the microstructure and mechanical properties of Y-TiAl. Intermetallics, 1999, 7(1): 89-99.

[18] Tian W H, Nemoto M. Effect of carbon addition on the microstructures and mechanical properties of $\mathrm{Y}$-TiAl alloys. Intermetallics, 1997, 5(3): 237-244.

[19] Niu H Z, Chen Y Y, Xiao S L, et al. Microstructure evolution and mechanical properties of a novel beta $\mathrm{Y}$-TiAl alloy. Intermetallics, 2012, 31: 225-231.

This work was financially supported by the Fundamental Research Funds for the Central Universities of Ministry of Education of China (Grant Nos. HEUCFP 201731 and 201719). 